\title{
Development and Validation of Stability Indicating HPLC Method for Simultaneous Estimation of Amoxicillin and Clavulanic Acid in Injection
}

\author{
Durga Mallikarjuna Rao Tippa*, Narendra Singh \\ National P.G. College, Jaunpur, India \\ E-mail: tdmrao@yahoo.in \\ Received September 26, 2010; revised October 24, 2010; accepted October 27, 2010
}

\begin{abstract}
A simple, fast, precise, accurate and rugged stability indicating high performance liquid chromatography (HPLC) method has been developed for simultaneous estimation of Amoxicillin and Clavulanic acid from injectable dosage form. The stability indicating capability of the method was proven by subjecting the drugs to stress conditions as per ICH recommended test conditions such as alkaline and acid hydrolysis, oxidation, photolysis, thermal degradation and resolution of the degradation products formed therein. The separation was obtained using a mobile phase composition at a ratio of 95:5 (v/v) of $\mathrm{pH} 5.0$ buffer and methanol on Inertsil C18 column $(250 \times 4.0 \mathrm{~mm}, 4 \mu \mathrm{m})$ with UV detection at $220 \mathrm{~nm}$ at a flow rate of $1 \mathrm{ml} / \mathrm{minute}$. The photodiode array detector was used for stress studies. The order of elution of peaks was Clavulanic acid followed by Amoxicillin. The linear calibration range was found to be 79.51 to $315.32 \mu \mathrm{g} / \mathrm{ml}$ for Amoxicillin and 17.82 to $67.90 \mu \mathrm{g} / \mathrm{ml}$ for Clavulanic acid. The Amoxicillin and Clavulanic acid were found to be stable in solution up to 24 hours. The method validation data showed excellent results for precision, linearity, specificity, limit of detection, limit of quantification and robustness. The present method can be successfully used for routine quality control and stability studies.
\end{abstract}

Keywords: Amoxicillin, Clavulanic Acid, HPLC, Stability Indicating

\section{Introduction}

Clavulanic acid is a novel beta-lactam compound which was isolated from the culture fluid of Streptomyces clavuligerus [1]. The compound is a potent inhibitor of a large number of beta-lactamase enzymes, which are responsible for the resistance of many bacteria to betalactam antibiotics [2]. In the presence of clavulanic acid, beta-lactamase labile penicillins are protected from degradation by cell-free beta-lactamase preparations and by whole bacterial cultures [3].

Amoxicillin-Clavulanate potassium, a semi-synthetic penicillin beta lactamase inhibitor combination drug, is a widely used oral antibiotic [4]. Amoxicillin-Clavulanic acid has been widely used as a prophylactic antibiotic in abdominal and gynecological surgery [5]. It is effective in the prevention of wound infections in operations in which the most likely pathogens are gram-negative, anaerobic, or mixed bacteria [6]. Chemically, Amoxicillin sodium is sodium (2S,5R.6R)-6-[®]-(-)-2-Amino-2-(P- hydroxyphenyl) acetamido]-3,3-dimethyl-7-oxo-4-thia-1azabicyclo[3.2.0] heptane-2-Carboxylate [7] and Clavulanate potassium is potassium (2)-(2R,5R)-3-(2-hydroxyethylidene)-7-oxo-4-1-azabicyclo[3.2.0]-heptane-2-carboxylate [8]. Both of these drugs are official in pharmacopoeias such as USP, BP etc. Several Amoxicillin and Clavulanic acid combinations are available in market in the form of tablet and suspension. In yester years injectable formulation has also been developed.

Literature survey reveals that several HPLC methods are reported for the determination of Amoxicillin [9-11] and Clavulanic acid [12,13] individually. However, no method is reported for simultaneous estimation of these two drugs in injectable formulation by HPLC.

In the present investigation, a specific stability indicating HPLC method is described for simultaneous estimation of these two drugs in injectable dosage form. Both the drugs were subjected to stress studies and the degradation products formed were separated from the main peaks. The proposed validated stability indicating 
method can be used for routine quality control and stability studies of the subjected formulation.

\section{Materials and Methods}

\subsection{Instrumentation}

The high pressure liquid chromatographic (HPLC) system was used of model Agilent 1100 series equipped with binary pump (G1312A), auto sampler (G1316A), thermo stated column compartment and variable wavelength detector (G1314A) controlled by the Chem station software. A HPLC system equipped with isocratic pump (G1310a), rheodyne injector (7725i) and photodiode array detector (G1315A) was used for degradation studies. A column Inertsil C18 HPLC column $(250 \times 4.0 \mathrm{~mm}, 4 \mu \mathrm{m})$ was used as a stationary phase.

\subsection{Materials}

Working standards of Amoxicillin trihydrate and Clavulanate potassium with lithium of potencies $86.12 \%$ (on as basis as Amoxicillin) and $42.11 \%$ (on as in basis as Clavulanic acid). Potassium dihydrogen phosphate monohydrate, sodium hydroxide and ortho-phosphoric acid were used of analytical reagent grade. HPLC grade methanol manufactured by E. Merck was procured from commercial source. HPLC grade water was obtained using millipore water purification system. Clavam $1.2 \mathrm{~g}$ (Amox- icillin and Clavulanate potassium for injection) is a dry powder injection contains Amoxicillin sodium equivalent to $1 \mathrm{~g}$ of Amoxicillin and Clavulanate potassium equivalent to $0.2 \mathrm{~g}$ of Clavulanic acid.

\subsection{Methods}

\subsubsection{Chromatographic Conditions}

The analysis was carried out on binary HPLC system using the column Inertsil C18 $(250 \times 4.0 \mathrm{~mm}, 4 \mu \mathrm{m})$ with UV-detection of $220 \mathrm{~nm}$ at ambient temperature using $20 \mu 1$ injection volume. For degradation studies, an isocratic pump and a photodiode array detector were used.

\subsubsection{Selection of Wavelength}

The bands of peaks are showing the maximum detection level for Amoxicillin in the range of $210 \mathrm{~nm}$ to $240 \mathrm{~nm}$ and Clavulanic acid in the range of $210 \mathrm{~nm}$ to $230 \mathrm{~nm}$. A single wavelength has selected for estimation of Amoxicillin and Clavulanic acid as $220 \mathrm{~nm}$ as both the peaks have the significant response. Overlaid spectrum of Amoxicillin and Clavulanic acid is given in Figure 1.

\subsubsection{Mobile Phase}

A degassed mixture of $(95: 5 \mathrm{v} / \mathrm{v}) \mathrm{pH} 5.0$ buffer $(7.8 \mathrm{~g}$ of sodium dihydrogen phosphate monohydrate was dissolved, diluted to $1000 \mathrm{ml}$ with water and adjusted the $\mathrm{pH}$ to $5.0 \pm 0.05$ using dilute ortho-phosphoric acid solution) and methanol.

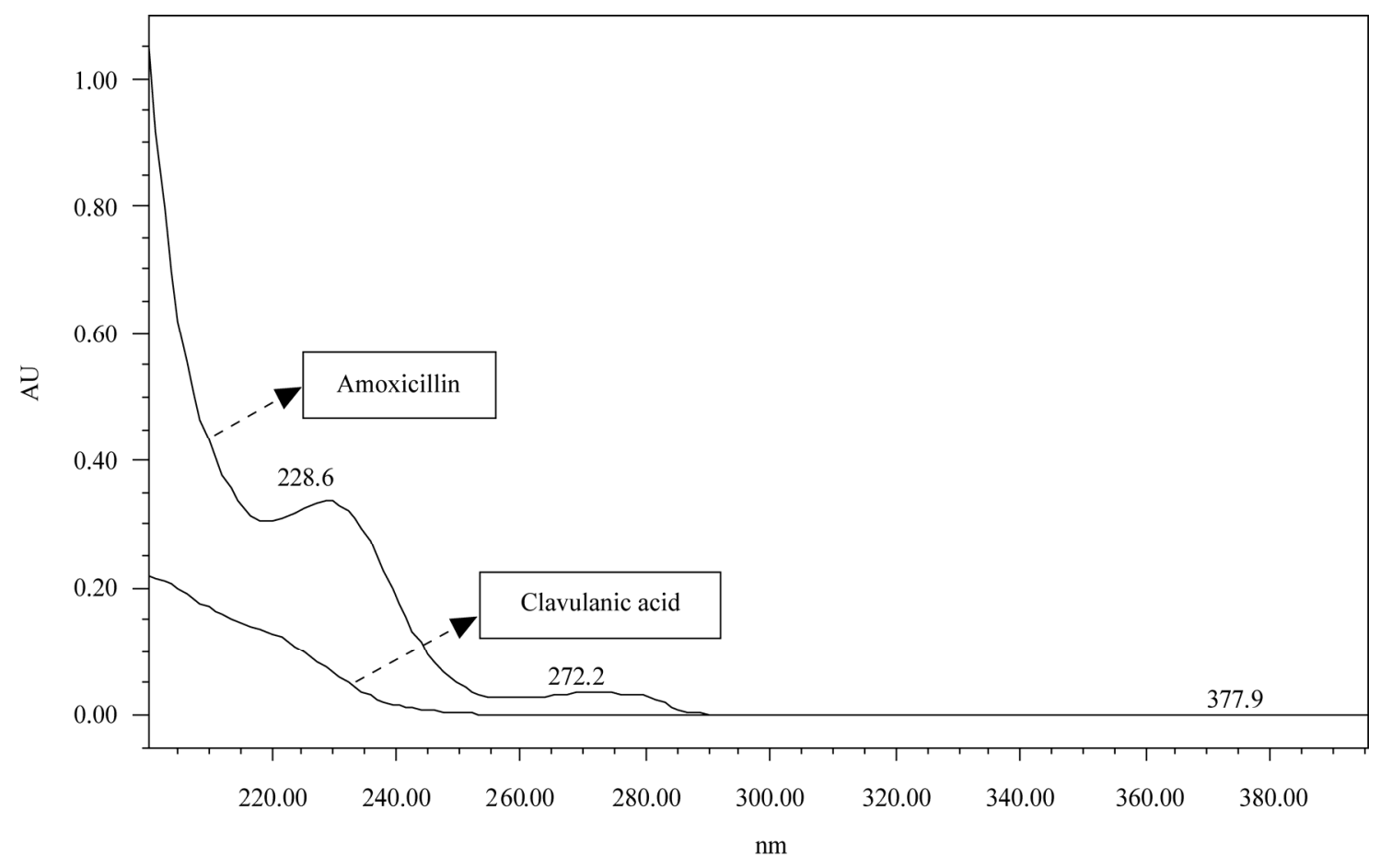

Figure 1. Overlaid spectrum of Amoxicillin and Clavulanic acid. 


\subsubsection{Standard Solution}

Standard stock solution was prepared by dissolving Amoxicillin trihydrate working standard equivalent to $100 \mathrm{mg}$ of Amoxicillin and Clavulanate potassium working standard equivalent to $20 \mathrm{mg}$ of Clavulanic acid in 60 $\mathrm{ml}$ of water and then diluted to $100 \mathrm{ml}$ with the same solvent. This stock solution was further diluted with water to get a solution of concentration $200 \mu \mathrm{g} / \mathrm{ml}$ of Amoxicillin and $40 \mu \mathrm{g} / \mathrm{ml}$ of Clavulanic acid. A typical chromatogram is given in Figure 2.

\subsubsection{Calibration}

Seven different concentration (79.51-315.32 $\mu \mathrm{g} / \mathrm{ml}$ of Amoxicillin and 17.82 to $67.90 \mu \mathrm{g} / \mathrm{ml}$ of Clavulanic acid) of mixture of Amoxicillin and Clavulanic acid were prepared for linearity studies. The responses were measured as peak areas and plotted against concentration.

\subsubsection{Estimation of Amoxicillin and Clavulanic Acid from Injectable Formulation}

Ten samples of Clavam $1.2 \mathrm{~g}$ were emptied completely and mixed. The pooled powder sample equivalent to about $20 \mathrm{mg}$ of Clavulanic acid and $100 \mathrm{mg}$ of Amoxicillin was transferred to dried $100 \mathrm{ml}$ volumetric flask. Dissolved and diluted to $100 \mathrm{~mL}$ with water. This stock solution was further diluted with water to get a solution of concentration $200 \mu \mathrm{g} / \mathrm{mL}$ of Amoxicillin and $40 \mu \mathrm{g} / \mathrm{ml}$ of Clavulanic acid. $20 \mu \mathrm{l}$ of each standard and test preparations were injected into the chromatography and the responses were recorded.

\subsection{Validation Parameters}

The method validation was carried out as per ICH guidelines [14]. Various method validation parameters ascertained are as follows.

\subsubsection{Precision}

Injection repeatability (System precision):

The injection repeatability was established by six replicate injections of the standard solution containing both the analytes of interest.

Sample repeatability (Method precision):

The sample repeatability was established by carrying out the analysis of the analytes six times.

\subsubsection{Specificity/Selectivity}

Specificity of the method was evaluated by injecting the blank, individual Amoxicillin, Clavulanic acid and sample solution prepared by spiking known impurities of Amoxicillin and Clavulanic acid (i.e., 6-Aminopenicillanic acid and p-Hydroxyphenyl glycine) in sample at $1 \%$ level of test concentration and injected into HPLC system to check the co-elution, if any, at the retention time of Amoxicillin peak and Clavulanic acid peak.

\subsubsection{Stress Testing (Forced Degradation)}

To further confirm the stability indicating nature of the analytical method, Amoxicillin and Clavulanate potassium were subjected to stress testing as per ICH recommended test conditions $[15,16]$. The drugs were subjected

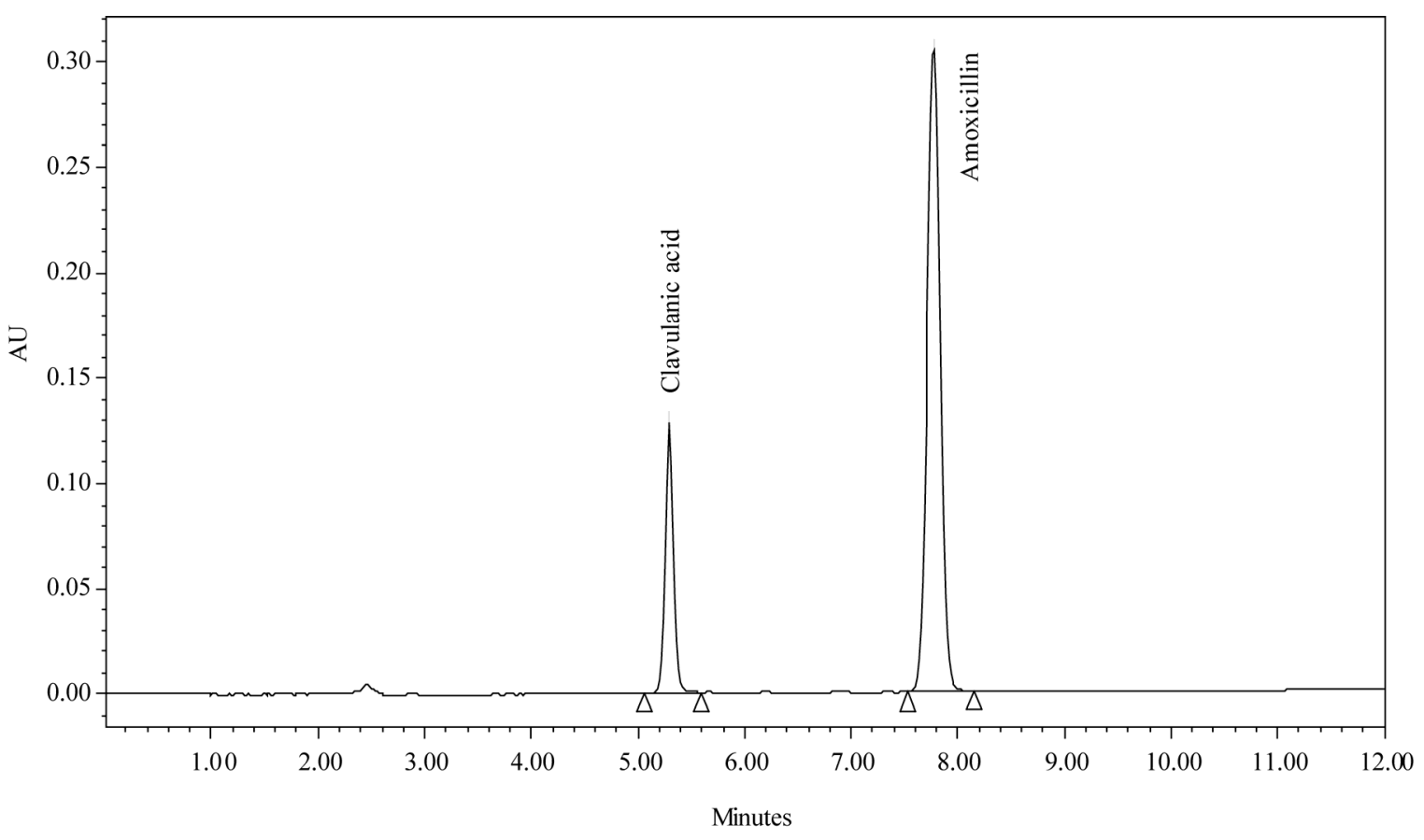

Figure 2. A typical chromatogram of standard. 
to acid hydrolysis by using $0.5 \mathrm{M}$ hydrochloric acid and base hydrolysis by using $0.1 \mathrm{~N}$ sodium hydroxide solution; oxidation by using $0.1 \% \mathrm{v} / \mathrm{v}$ solution of hydrogen peroxide; thermal and photolysis.

The objective of stress study was to generate the degradation products under various stress conditions. The stress conditions varied both in terms of temperature and time from moderate to extreme to achieve the appropriate degradation. The spectral purity of the main peaks was evaluated using photodiode array detector and chemstation to verify that the degradation peaks are well resolved from the main peaks.

\subsubsection{Limit of Detection and Limit of Quantitation}

The limit of detection (LOD) and the limit of quantitation (LOQ) for Amoxicillin and Clavulanic acid were determined.

\subsubsection{Ruggedness (Intermediate Precision)}

The ruggedness of the method was demonstrated by analysis of the sample by using other column of same brand with same specification and other instrument of same brand and same configuration (Waters alliance HPLC with Empower software). The percent relative standard deviation (\% RSD) of two sets of data indicates the ruggedness of the method and t-test was performed.

\subsubsection{Robustness}

The robustness of the method was determined as a measure of the analytical method capability to be unaffected by small variations in method parameters. The different variations such as variation in flow rate by $\pm 0.2 \mathrm{ml} /$ minute; variation in wavelength by $\pm 2 \mathrm{~nm}$, variation in temperature by $\pm 5^{\circ} \mathrm{C}$, variation in composition of mobile phase $\pm 5 \%$ absolute (in terms of organic component) and variation in $\mathrm{pH}$ of buffer by \pm 0.2 units. At these changed conditions, the standard and sample solutions were injected. The system suitability was evaluated in each varied condition. The amounts of Amoxicillin and Clavulanic acid were calculated from sample solution in each varied condition.

\subsubsection{Stability of the Solution}

A sample solution of Amoxicillin and Clavulanate potassium for injection was prepared and analyzed initially and also at different time intervals by keeping the solution at room temperature.

\subsubsection{System Suitability Tests}

System suitability was verified by injecting standard solution on various days of the validation. The percent RSD was verified from the replicate injections of standard solution. Various parameters such as tailing factor and resolution between the peaks of Amoxicillin and Clavulanic acid were obtained.

\section{Results and Discussion}

\subsection{Precision}

The values of the relative standard deviation of six replicate injections of the standard solution containing both the analytes of interest lie well within the limits (\% RSD $\leq 2.0$ ), indicating the injection repeatability of the method. The values of the percent relative standard deviation for sample repeatability also lie well within the limits $(\% \mathrm{RSD} \leq 2.0)$ indicating the sample repeatability of the method. The results are given in Table 1.

\subsection{Specificity/Selectivity}

There was no interference from the blank and also from the impurities (i.e., 6-Aminopenicillanic acid and p-Hydroxyphenyl glycine) at the retention time of Amoxicillin and Clavulanic acid peaks. The peak purity data shows the peaks are pure and there was no co-eluting peak at the retention time of Amoxicillin peak and Clavulanic acid peaks.

Table 1. Compiled data of method precision and ruggedness.

\begin{tabular}{|c|c|c|c|c|}
\hline \multirow{2}{*}{ S. No. } & \multicolumn{2}{|c|}{$\begin{array}{l}\% \text { Assay of } \\
\text { Amoxicillin }\end{array}$} & \multicolumn{2}{|c|}{$\begin{array}{c}\% \text { Assay of } \\
\text { Clavulanic acid }\end{array}$} \\
\hline & I & II & I & II \\
\hline 1. & 99.25 & 99.10 & 103.41 & 103.72 \\
\hline 2. & 98.81 & 99.50 & 106.94 & 103.41 \\
\hline 3. & 99.11 & 99.29 & 102.71 & 102.81 \\
\hline 4. & 100.21 & 100.10 & 102.41 & 102.79 \\
\hline 5. & 98.71 & 101.57 & 106.14 & 100.39 \\
\hline 6. & 101.72 & 101.65 & 102.01 & 99.97 \\
\hline Mean. & 99.85 & 99.41 & 104.19 & 101.94 \\
\hline SD & 1.851 & 1.751 & 1.944 & 1.740 \\
\hline$\%$ RSD & 1.87 & 1.75 & 1.85 & 1.69 \\
\hline Overall Mean. & \multicolumn{2}{|c|}{99.49} & \multicolumn{2}{|c|}{104.015} \\
\hline Overall SD & \multicolumn{2}{|c|}{1.801} & \multicolumn{2}{|c|}{1.842} \\
\hline Overall \% RSD & \multicolumn{2}{|c|}{1.81} & \multicolumn{2}{|c|}{1.77} \\
\hline
\end{tabular}

I-Method Precision, II-Ruggedness. 


\subsection{Stress Testing (Forced Degradation)}

The \% degradation of Amoxicillin in acid hydrolysis, base hydrolysis, oxidation, thermal and photolytic was $6.65,6.21,5.01,13.12$ and 8.59 respectively. The \% degradation of Clavulanic acid in acid hydrolysis, base hydrolysis, oxidation, thermal and photolytic was 23.21, $14.41,0.00,17.80$ and 10.21 respectively. Peak purity was also found to be passed. The peaks of the degradation products were well resolved from the peaks of the main component. The results of the stress studies are tabulated in Tables 2(a) and 2(b).

\subsection{LOD and LOQ}

The LOD and LOQ for Amoxicillin and Clavulanic acid were found to be $3.98 \mu \mathrm{g} / \mathrm{ml}$ and $12.06 \mu \mathrm{g} / \mathrm{ml}$ for Amoxicillin and $7.13 \mu \mathrm{g} / \mathrm{ml}$ and $21.62 \mu \mathrm{g} / \mathrm{ml}$ for Clavulanic acid, respectively.

\subsection{Ruggedness (Intermediate Precision) \& Robustness}

The percent relative standard deviation (\% RSD) of two sets of data indicates the ruggedness of the method. Further, the t-test was performed on the data and the differ- ence was found to be not significant. The compiled data of method precision and ruggedness are given in Table 1. The method is not affected by the deliberate variations such as flow rate, wavelength, mobile phase composition, temperature and $\mathrm{pH}$.

\subsection{Linearity}

Calibration curve obtained by the least square regression analysis between average peak area and concentration showed linear relationship with a correlation coefficient of 0.99980 .9994 for Amoxicillin and Clavulanic acid respectively over the calibration ranges tested.

The linear calibration range was found to be 79.51 to $315.32 \mu \mathrm{g} / \mathrm{ml}$ for Amoxicillin and 17.82 to $67.90 \mu \mathrm{g} / \mathrm{ml}$ for Clavulanic acid. The linearity of the calibration curves indicated the suitability of the method over a wide range of concentration of both the actives.

Linear regression least square fit data obtained from the calibration curves are given in Tables 3(a) and 3(b).

\subsection{System Suitability and Stability of Analytical Solution}

The tailing of Amoxicillin and Clavulanic acid were in the range of $0.96-0.99$ and $1.07-1.14$ respectively. The \%

Table 2. (a) Forced degradation for Amoxicillin.

\begin{tabular}{ccccc}
\hline Mode of Degradation & Condition & \% Assay & \% Degradation w. r. t control & Peak purity data \\
\hline Control & No treatment & 101.80 & - & 998.31 \\
Acid & $0.5 \mathrm{~N} \mathrm{HCl}(2 \mathrm{hrs})$ & 97.10 & 6.65 & 998.64 \\
Base & $0.1 \mathrm{~N} \mathrm{NaOH}(0 \mathrm{hrs})$ & 96.42 & 6.21 & 992.71 \\
Oxidation & $0.1 \% \mathrm{v} / \mathrm{v} \mathrm{H}_{2} \mathrm{O}_{2}(0 \mathrm{hrs})$ & 98.21 & 5.01 & 998.63 \\
Thermal & $50^{\circ} \mathrm{C}(3 \mathrm{hrs})$ & 88.92 & 13.12 & 998.39 \\
Photolytic & $\mathrm{UV}$-light $(3 \mathrm{hrs})$ & 95.21 & 8.59 & 998.78 \\
\hline
\end{tabular}

Table 2. (b) Forced degradation for Clavulanic acid.

\begin{tabular}{ccccc}
\hline Mode of Degradation & Condition & \% Assay & \% Degradation w. r. t control & Peak purity data \\
\hline Control & No treatment & 101.27 & - & 999.21 \\
Acid & $0.5 \mathrm{~N} \mathrm{HCl}(2 \mathrm{hrs})$ & 78.91 & 23.21 & 999.90 \\
Base & $0.1 \mathrm{~N} \mathrm{NaOH}(0 \mathrm{hrs})$ & 87.72 & 14.41 & 999.43 \\
Oxidation & $0.1 \% \mathrm{v} / \mathrm{v} \mathrm{H}_{2} \mathrm{O}_{2}(0 \mathrm{hrs})$ & 108.44 & - & 998.40 \\
Thermal & $50^{\circ} \mathrm{C}(3 \mathrm{hrs})$ & 84.21 & 17.80 & 999.10 \\
Photolytic & $\mathrm{UV}$-light(3 hrs $)$ & 91.39 & 10.21 & 999.11 \\
\hline
\end{tabular}


Table 3. (a) Linearity of response for Amoxicillin.

\begin{tabular}{|c|c|c|}
\hline S. No. & Conc. $(\mu \mathrm{g} / \mathrm{ml})$ & Peak area \\
\hline 1. & 79.51 & 2322.80 \\
\hline 2. & 118.70 & 3458.52 \\
\hline 3. & 158.21 & 4674.12 \\
\hline 4. & 197.67 & 5767.28 \\
\hline 5. & 236.81 & 6972.31 \\
\hline 6. & 276.21 & 8067.69 \\
\hline 7. & 315.32 & 9187.91 \\
\hline Slope. & \multicolumn{2}{|c|}{29.18} \\
\hline Intercept & \multicolumn{2}{|c|}{43.34} \\
\hline Correlation Coefficient & \multicolumn{2}{|c|}{0.9998} \\
\hline
\end{tabular}

Table 3. (b) Linearity of response for Clavulanic acid.

\begin{tabular}{|c|c|c|}
\hline S. No. & Conc. $(\mu \mathrm{g} / \mathrm{ml})$ & Peak area \\
\hline 1. & 17.82 & 610.35 \\
\hline 2. & 26.11 & 708.51 \\
\hline 3. & 34.38 & 1226.31 \\
\hline 4. & 42.80 & 1509.10 \\
\hline 5. & 51.09 & 1820.12 \\
\hline 6. & 59.58 & 2095.61 \\
\hline 7. & 67.90 & 2485.09 \\
\hline Slope. & \multicolumn{2}{|c|}{35.44} \\
\hline Intercept & \multicolumn{2}{|c|}{26.14} \\
\hline Correlation Coefficient & \multicolumn{2}{|c|}{0.9994} \\
\hline
\end{tabular}

RSD for five replicate injections of standard was found in the range of 0.03-0.05 for Amoxicillin peak and 0.130.31 for Clavulanic acid peak. Resolutions between the peaks were found in the range of 12.01-13.21. The resolution, tailing factor and \% RSD values are given in Table 4.

The peaks of Amoxicillin and Clavulanic acid were found to be symmetrical and well defined, free from tailing. The elution order was Clavulanic acid first at retention time of about 5.3 minutes followed by Amoxicillin at retention time of about 7.5 minutes. The sensitivity of the method using the said method was found to be good. The total run time of each analysis is about 12 minutes, which is rapid and economical considering the
Table 4. System suitability.

\begin{tabular}{|c|c|c|c|c|c|}
\hline \multirow{2}{*}{ Experiment } & \multirow{2}{*}{$\mathrm{R}$} & \multicolumn{2}{|c|}{$\%$ RSD } & \multicolumn{2}{|c|}{ Tailing factor } \\
\hline & & $\begin{array}{c}\text { Amoxicillin } \\
\text { peak }\end{array}$ & $\begin{array}{c}\text { Clavulanic } \\
\text { acid peak }\end{array}$ & $\begin{array}{l}\text { Amoxicillin } \\
\text { peak }\end{array}$ & $\begin{array}{l}\text { Clavulanic } \\
\text { acid peak }\end{array}$ \\
\hline $\begin{array}{l}\text { Method } \\
\text { precision }\end{array}$ & 12.01 & 0.04 & 0.13 & 0.99 & 1.14 \\
\hline Stress study & 13.21 & 0.05 & 0.29 & 0.96 & 1.12 \\
\hline Linearity & 12.32 & 0.03 & 0.14 & 0.99 & 1.14 \\
\hline Ruggedness & 12.60 & 0.03 & 0.31 & 0.96 & 1.07 \\
\hline
\end{tabular}

stability indicating nature of the method. The sample solutions were found to be stable up to 24 hours.

\section{Conclusions}

The analytical method is simple, specific, rugged and stability indicating. Hence it can be used for routine quality control analysis as well as stability studies of injection and might be useful for other pharmaceutical dosage forms. The developed method is stability indicating and it is LOD and LOQ values are in the range of $3.98 \mu \mathrm{g} / \mathrm{ml}$ and $12.06 \mu \mathrm{g} / \mathrm{ml}$ for Amoxicillin and $7.13 \mu \mathrm{g} / \mathrm{ml}$ and $21.62 \mu \mathrm{g} / \mathrm{ml}$ for Clavulanic acid. This method is sensitive and superior to the published methods since those are neither stability indicating nor LOD and LOQ values are estimated at low level.

\section{Acknowledgements}

The help rendered by T.D.P.G College for providing the facilities of their laboratory at Jaunpur, Uttar Pradesh was gratefully acknowledged. The author also thanks to Dr. A. N. Thakur, M.Sc, Ph.D. Professor, Department of Physics, and T.D.P.G. College for his support.

\section{References}

[1] C. Reading and M. Cole, "Clavulanic Acid: A Beta Lactamase-Inhibiting Beta-Lactam from Streptomyces Clavuligerus," Antimicrobial Agents and Chemotherapy, Vol. 11, No. 5, 1977, pp. 852-857.

[2] M. Foulstone and C. Reading, "Assay of Amoxicillin and Clavulanic Acid, the Component of Augmentin, in Biological Fluids with High Performance Liquid Chromatography," Antimicrobial Agents and Chemotherapy, Vol. 22, No. 5, November 1982, pp. 753-762.

[3] P. A. Hunter, K. Coleman, J. Fisher, D. Taylor and E. Taylor, "Clavulanic Acid, a Novel B-Lactam with Broad Spectrum B-Lactamase Inhibitory Properties. Synergistic Activity with Ampicillin and Amoxicillin," Drugs Under 
Experimental and Clinical Research, Vol. 5, 1979, pp. 1-6.

[4] K. R. Reddy, P. Brillant and E. R. Schiff, "Amoxicillin-Clavulanate Potassium Associated Cholestasis," Gastroenterology, Vol. 96, No. 4, April 1989, pp. 135-141.

[5] C. Hall, F. Curran, D. W. Burdon and M. R. B. Keighley, "A Randomized Trial to Compare Amoxicillin and Clavulanate with Metonidazole Plus Gentamycin in Prophylaxis in Elective Colarectl Suregery," Journal of Antimicrobial Chemotherapy, Vol. 24, No. (Suppl)B, 1989, pp. 195-208.

[6] A. P. R. Willson, S. Shrimpton and M. Jaderberg, "A Meta Analysis of the Use of Amoxicillin-Clavulanic Acid in Surgical Prophylaxis," Journal of Hospital Infection, Vol. 22, No. (Suppl)A, 1992, pp. 9-21.

[7] The Department of Health, "British Pharmacopoeia," DH, London, Vol. I, 2009, pp. 353-361.

[8] "Physicians' Desk Reference," 60th Edition, Thomson PDR Company, Montvale, 2006, p. 1331.

[9] J. B. Veer, Y. A. Hekster, A. M. Baars and E. Van Der Klerjn, "Rapid Determination of Amoxicillin and Ampicillin in Body Fluids by Means of High Performance Liquid Chromatography," Journal of Chromatography, Vol. 1145, 1978, pp. 496-501.

[10] M. J. Lebella, W. L. Wilson and G. Lawriault, "High Performance Liquid Chromatographic Determination of
Amoxicillin in Pharmaceutical Dosage Forms," Journal of Chromatography, Vol. 202, No. 1, 1980, pp. 144-147.

[11] De Pourcq, J. Hoebus, E. Roets, J. Hoogmartens and H. Vanderhaeghe, "Quantiative Determination of Amoxicillin and Its Decomposition Products by High Performance Chromatography," Journal of Chromatography, Vol. 321, 1985, pp. 441-443.

[12] A. S. Low, R. B. Taylor and J. M. Gould, "Determination of Clavulanic Acid by a Sensitive HPLC Method," Journal of Antimicrobial Chemotherapy, Vol. 24, No. (Suppl)B, 1989, pp. 83-86.

[13] J. Haginaka, T. Nakagawa, Y. Nishind and T. Uno, "High Performance Liquid Chromatography Determination of Clavulanic Acid in Human Urine," Journal of Antibiotics, Vol. 34, 1981, pp. 1189-1194.

[14] ICH, "Validation of Analytical Procedures: Text and Methodology," International Conference on Harmonisation Guidance Documents, Q2(R1), 2005.

[15] ICH, "Photo Stability Testing of New Drug Substances and Products," International Conference on Harmonisation Guidance Documents, Q1B, 2005.

[16] ICH, "Stability Testing of New Drug Substances and Products," International Conference on Harmonisation Guidance Documents, Q1A(R2), 2005. 